\title{
Is there truly an increase in risk of cardiovascular and hematological adverse events with vascular endothelial growth factor receptor tyrosine kinase inhibitors?
}

\section{Luis Furuya-Kanamori, Suhail AR Doi, Adedayo Onitilo \& Saghir Akhtar}

To cite this article: Luis Furuya-Kanamori, Suhail AR Doi, Adedayo Onitilo \& Saghir Akhtar (2019): Is there truly an increase in risk of cardiovascular and hematological adverse events with vascular endothelial growth factor receptor tyrosine kinase inhibitors?, Expert Opinion on Drug Safety, DOI: 10.1080/14740338.2020.1691167

To link to this article: https://doi.org/10.1080/14740338.2020.1691167

Accepted author version posted online: 07

Nov 2019.

Submit your article to this journal $\pi$

Q View related articles 5

View Crossmark data $₫$ 
Publisher: Taylor \& Francis \& Informa UK Limited, trading as Taylor \& Francis Group

Journal: Expert Opinion on Drug Safety

DOI: $10.1080 / 14740338.2020 .1691167$

Is there truly an increase in risk of cardiovascular and hematological adverse events with vascular endothelial growth factor receptor tyrosine kinase inhibitors?

Luis Furuya-Kanamori ${ }^{1}$, Suhail AR Doi ${ }^{2}$, Adedayo Onitilo ${ }^{3}$ and Saghir Akhtar ${ }^{4}$

${ }^{1}$ Research School of Population Health, ANU College of Health and Medicine, Australian National University, Acton, Australia

${ }^{2}$ Department of Population Medicine, College of Medicine, Qatar University, Doha, Qatar ${ }^{3}$ Department of Hematology/Oncology, Marshfield Clinic, Weston, Wisconsin, USA ${ }^{4}$ Department of Basic Medical Sciences, College of Medicine, Qatar University, Doha, Qatar

\section{Corresponding author:}

Luis Furuya-Kanamori,

Research School of Population Health, ANU College of Health and Medicine, Australian National University, A: 62 Mills Road, Acton, ACT, Australia Email: luis.furuya-kanamori@anu.edu.au 


\begin{abstract}
Objectives: Recent studies have shown an increase risk of cardiovascular and hematological adverse events associated with vascular endothelial growth factor tyrosine kinase inhibitors (VEGF-TKIs). The authors hypothesize that the original studies may have produced exaggerated results because of the small baseline risks involved.
\end{abstract}

Methods: A meta-analysis that included 71 trials, 8 different VEGFR-TKIs, and 11 adverse events was re-analyzed. The outcome of interest was re-defined as the complementary outcome (i.e. remaining free of an adverse event). The inverse variance heterogeneity model was used to pool the effect size.

Results: VEGFR-TKIs decreased the risk of remaining free of hypertension by $7 \%$ (RR 0.93; 95\%Cl:0.88-0.97). Specific VEGFR-TKIs; pazopanib, regorafenib, and nintedanib were associated with a decrease risk of remaining free of an arterial thrombotic event (RR 0.96; 95\%Cl:0.93-0.99), thrombocytopenia (RR 0.91; 95\% Cl:0.89-0.93), and bleeding (RR 0.96; 95\% Cl:0.93-0.99) respectively. VEGFRTKIs were not associated with thrombotic event, myocardial infarction, stroke, venous thrombotic event, pulmonary embolism, left ventricular dysfunction, or QTC interval prolongation.

Conclusion: VEGFR-TKIs are associated with a small increase in risk of patients developing hypertension, arterial thrombotic events, thrombocytopenia, and bleeding. Previous studies overestimated the actual risk associated with VEGFRTKIs by analyzing the outcome with the lower baseline risk.

Key words: tyrosine kinase inhibitors, risk, cardiovascular events, adverse events, meta-analysis 


\section{Introduction}

An important requirement for tumor growth, survival and progression is the formation of new blood vessels (i.e. angiogenesis) to provide it with vital nutrients and oxygen [1]. Although multiple signaling mechanisms are involved in promoting tumor angiogenesis, the vascular endothelial growth factor (VEGF)- VEGF receptor (VEGFR) axis is one of the most important, making it a target for cancer therapy [2]. Commercially available therapeutic strategies targeting the VEGF signaling pathway amongst other mechanisms of action include small molecule receptor tyrosine kinase inhibitors (TKIs) such as axitinib, levantinib, nintedanib, pazopanib, regorafenib, sorafenib, sunitinib, and vandetanib which block the kinase activity of one or more of the VEGFRs [3]. However, currently available TKIs do not just target VEGFRs, but also can inhibit the kinase activity of other cell surface receptors such as plateletderived growth factor receptors, epidermal growth factor receptor, as well as intracellular signaling protein kinases such as RAF and thus are considered multitargeted anti-angiogenic drugs or multi-kinase inhibitors [3,4]. Because of the multitargeted nature of these inhibitors and the essential role of the VEGR-VEGFR axis in normal endothelial physiology especially in vascular homeostasis, several toxicities have been reported with anti-VEGF therapy [3,5,6].

After the approval of VEGFR TKIs by the FDA, two meta-analyses by the same group of researchers investigated the association between VEGFR TKIs and adverse events and concluded that treatment with VEGFR TKIs is associated with increased risk of arterial thromboembolic events (relative risk [RR] 3.03; 95\% Cl 1.25 to 7.37) [7] and fatal adverse events (RR 2.23; $95 \% \mathrm{Cl} 1.12$ to 4.44) [8]. However, close examination of the individual studies, revealed that the proportion of adverse events (i.e. baseline risk) was very small ranging from $0 \%$ to $3 \%$.

In this paper, we re-examine the risk of adverse events for VEGFR TKIs and argue that the observed risk associated with the treatment was influenced by the selection of the outcome with the smaller baseline risks. We will demonstrate how such an exaggeration can occur and propose a simple solution with a re-analysis of an up to date meta-analysis, and discuss the implications of the results.

\section{Methods}

\subsection{Data source}


Since the publication by Choueiri et al. (2010) [7] and Schutz et al. (2012) [8], additional VEGFR TKIs have been approved by the FDA and several randomized controlled have been conducted and reported VEGFR TKIs adverse events. Therefore, we searched for the most updated meta-analysis on the topic for our reanalysis and found a publication by Totzeck et al. [9] from 2018 that included 71 randomized controlled trials (nearly 29,000 participants), 8 different VEGFR TKIs (axitinib, levantinib, nintedanib, pazopanib, regorafenib, sorafenib, sunitinib, and vandetanib), and 11 cardiovascular and hematological adverse outcomes (thrombotic event, arterial thrombotic event, myocardial infarction, stroke, venous thrombotic event, pulmonary embolism, bleeding, thrombocytopenia, left ventricular dysfunction, QTc interval prolongation, and hypertension).

\subsection{Exaggeration of the effect estimate}

It is well-known that RRs are asymmetric, thus the RR for an outcome (e.g. adverse event) can be markedly different from the RR of its complementary outcome (e.g. no adverse event). The asymmetry occurs because the RR is magnified only at low baseline risks, while remains stable at high baseline risks [10]. A simple way to handle the issue of RR magnification at low baseline risks with mutually exclusive binary outcomes, is to re-define the outcome to the complementary outcome (the one with the higher baseline risk).

For example, if 3 out of 100 participants in the intervention arm, and 2 in 100 in the control arm present an adverse event; the RR adverse event $=1.5$, which is interpreted as a $50 \%$ increase in risk of adverse event with the intervention compared to the control. However, the outcome of interest can be redefined to 97 and 98 participants with non-adverse events in the intervention and control arm, respectively. This would provide a RR non-adverse events $=0.99$, which can be interpreted as a $1 \%$ increase in risk of an adverse events. The RR of the complementary outcome (i.e. non-adverse events) is in line with the absolute effect measure (i.e. risk difference) of $1 \%$ increase in risk of an adverse event.

Furthermore, the use of the complementary outcome would prevent study arms to have zero events thus the application of continuity correction would no longer be necessary. Many statistical software apply a continuity correction factor (usually 0.5 ) to handle zero events in an arm; however, it has been noted that such a correction can introduce serious bias [11].

\subsection{Statistical analysis}


To elucidate the risk of adverse events with VEGFR TKIs, data reported by Totzeck et al.[9] were re-analyzed using the complementary outcomes - remaining free of an adverse event. The pooled RR was computed for each of the 11 outcomes and for each specific VEGFR TKIs using the inverse variance heterogeneity (IVhet) model [12].

In addition, to assess the detriment accrued to the patient, an absolute effect size, the number needed to harm $(\mathrm{NNH})$ was estimated as the inverse of the product of the relative risk reduction and the baseline risk in the control group for the associations that were found to be statistically significant. The presence of publication bias for the 11 complementary outcomes were assessed using the Doi plots and LFK index [13]. The analysis was conducted in MetaXL version 5.3 (http://www.epigear.com).

\section{Results}

Table 1 shows the updated risk profile for VEGFR TKls using the complementary outcome for 11 adverse events. There was no association between VEGFR TKIs and remaining free of a thrombotic event, myocardial infarction, stroke, venous thrombotic event, pulmonary embolism, left ventricular dysfunction, or QTC interval prolongation.

One trial [14] assessed the association between pazopanib and arterial thrombotic event. Pazopanib was associated with a decrease in risk of remaining free of an arterial thrombotic event (RR $0.96 ; 95 \% \mathrm{Cl} 0.93-0.99)$, this findings translates into a NNH of $26(95 \% \mathrm{Cl} 15-132)$ patients (Table 1 and Supplementary material S1). The association between regorafenib and remaining free of thrombocytopenia was assessed by four trials [15-18] and it was found that regorafenib decreased the risk of remaining free of thrombocytopenia by $9 \%$ (RR $0.91 ; 95 \% \mathrm{Cl}$ 0.89-0.93) compared to placebo. The $\mathrm{NNH}$ for regorafenib was 12 $(95 \% \mathrm{Cl} 10-15)$ patients to observed one additional event of thrombocytopenia (Table 1 and $\mathrm{S} 1)$.

The results revealed an increased risk of bleeding. Two trials $[19,20]$ found that nintedanib was associated with a decrease in risk of $4 \%(\mathrm{RR} 0.96$; $95 \% \mathrm{Cl} 0.93-$ $0.99)$ of remaining free of bleeding, with an $\mathrm{NNH}$ of $28(95 \% \mathrm{Cl} 17-104)$. One trial found a strong association with sunitinib as it decreased the risk of remaining free of 
bleeding by $51 \%(\mathrm{RR} 0.49 ; 95 \% \mathrm{Cl} 0.34-0.69)$ with an $\mathrm{NNH}$ of $2(95 \% \mathrm{Cl} 1-4)$ (Table 1, Figure 1, and S1).

Overall VEGFR TKIs decrease the risk of remaining free of hypertension by $7 \%$ (RR 0.93; 95\%Cl 0.88-0.97). Levantinib (RR 0.35; 95\% Cl 0.29-0.43), pazopanib (RR 0.64; 95\%Cl 0.48-0.86), regorafenib (RR 0.79; 95\% Cl 0.72-87), and sorafenib ( $\mathrm{RR} 0.92 ; 95 \% \mathrm{Cl} 0.85-0.99$ ) were found to decrease the risk of remaining free of hypertension. The NNH for levantinib, pazopanib, regorafenib, and sorafenib were 2 $(95 \% \mathrm{Cl} 1-3), 4(95 \% \mathrm{Cl} 3-10), 6(95 \% \mathrm{Cl} 4-9)$, and $12(95 \% \mathrm{Cl} 7-117)$, respectively (Table 1, Figure 2, and S1).

On examination of the Doi plots and LFK indexes, there was evidence of publication bias towards selective publication reporting an increase in risk of an adverse event for stroke, venous thrombotic events, bleeding, thrombocytopenia, left ventricular dysfunction, QTc interval prolongation, and hypertension; while it was towards publications reporting a decrease in risk for thrombotic events (S2).

\section{Discussion}

The re-analysis of the meta-analysis by Totzeck et al. [9] using the complementary outcome revealed that VEGFR TKIs increase the overall risk of developing hypertension by around $7 \%$, but this was particularly significant with levantinib, pazopanib, regorafenib, and sorafenib. There was no overall class-related risk of developing any of the other cardiovascular adverse effects studied, although increased risk with specific VEGFR TKIs was noted for some adverse effects. The risk of developing arterial thrombotic events was increased with pazopanib, thrombocytopenia with regorafenib, and bleeding modestly with nintedanib and most significantly with sunitinib.

The fact that our re-analysis of the adverse effects reported for VEGFR TKIs showed that overall increased risk for the 8 drugs studied was only noted for hypertension confirms that elevated blood pressure is the most common cardiovascular complication associated with these therapeutic agents [21,22]. Although, we only found statistically significant increase in the risk of developing hypertension with 4 out of the 8 TKIs studied, the remaining not statistically significant results showed a trend toward an increased risk of developing hypertension implying that this adverse effect represents a drug class effect. This is supported by the finding that TKI-induced hypertension is known to be drug dose- 
dependent and because its presence is closely correlated with the potency of VEGFR-2 inhibition, it arises from on-target inhibition rather than off-target effects [6]. Thus, TKIs with higher rates of hypertension, such as Levantinib are generally thought to have higher affinity for VEGFR-2 than those TKIs having little or no rates of hypertension such as sorafenib and sunitinib, which tend to bind to other targets with greater affinity [6]. When present, the increase in blood pressure with TKIs occurs rapidly, generally within a few hours of the beginning of therapy in patients, and appears to be reversible upon its discontinuation [3]. Patients with a history of hypertension and those treated with multiple VEGF/VEGFR pathway inhibitors are at particularly high risk [23].

Additional factors that might also account for the variation in $\mathrm{RR}$ of developing hypertension (and possibly other vascular adverse effects) across the class of TKIs studied herein include 1) possible under-reporting of hypertension, most probably as a result of the different classifications and definitions used among the different clinical trials and infrequent blood pressure measurements in the outpatient setting [24,25]; 2) exclusion of patients with difficult to treat hypertension and/or a history of cardiovascular disease from some clinical trials [22,26]; 3) the type and grade of the cancer (e.g. incidence of hypertension is relatively higher in patients with renal cell carcinoma than in hepatocellular carcinoma for sorafenib and gastrointestinal stromal tumors for sunitinib [27]; and 4) the exact medications being taken by the patient. For example, patients on combination therapy with multiple anti-VEGF therapies result in higher incidences of hypertension [22]. Furthermore, since many of the VEGFR TKIs undergo metabolisms by CYP3A4 [28], pharmaco-genetic variations (e.g. SNPs) in this enzyme might also account for the observed variations between trials/TKIs as well as by co-treatment of patients with medications that are either inducers or inhibitors of CYP3A4.

The precise mechanisms for VEGFR TKI-induced vascular toxicities of hypertension (observed in 4 out of 8 VEGFR TKIs), increased risk of bleeding (as observed predominantly with sunitinib) and arterial thrombosis (with pazopanib) are not completely understood but most likely involve disruption of the key roles of VEGF-VEGFR axis in maintaining normal endothelial function. Generalized endothelial dysfunction predisposes to vasoconstriction, atherosclerosis, platelet activation, thrombosis (arterial more than venous), and paradoxically even hemorrhaging/ bleeding [9]. The role of endothelial dysfunction in TKI-mediated 
vascular toxicities is also supported by a recent study by Dalbeni et al. (2019) [29] who noted alterations in some endothelial-related factors, such as u-nitrates, $\mathrm{p}$-ET1 , and proteinuria associated with hypertension in a group of patients with renal cell carcinoma. Inhibition of VEGF/VEGFR signaling by TKIs is thought to induce: 1) endothelial alterations in nitric oxide (NO) production and possibly ET-1 levels that result in an imbalance between vasodilator and vasoconstrictor signaling [3]; 2) a reduction in capillary density possibly through apoptosis and vascular remodeling [30]; 3) oxidative stress [26,31]; 4) increased arterial stiffness [32]; 5) decrease in endothelial cell renewal, making vessels weak and susceptible to further damage induced by trauma including bleeding [33]; and 6) a decrease in matrix deposition in sub endothelial layers of the vasculature may also induce bleeding [34].

All these changes cause arterial hypertension and alteration of the vascular integrity that can predispose to bleeding. Furthermore, VEGF-VEGFR inhibition alters vascular homeostasis through a molecular mechanism involving the interaction between platelets and endothelial cells, eventually causing both thrombosis and hemorrhage [6,35]. VEGFR TKI may promote a prothrombotic state through inhibition of prostacyclin and NO production by endothelial cells, both of which have antiplatelet actions [36], formation of immune complexes that activate platelets [37] and/or through increased hematocrit and blood viscosity [38]. All the above mechanisms could explain the incidence of TKI-induced vascular adverse events analyzed herein but the relative contributions of each pathophysiological mechanism to the overall risk remains to be determined $[9,39]$.

As to why only some of the VEGF TKIs result in a particular vascular adverse effect is not clear, as most of these are predominantly thought to be VEGF-VEGFR inhibitor class effects. Differences may result from drug specific factors (variations in the actual molecular drug targets especially for multi-targeted TKIs; differences in target affinity and pharmacodynamics), patient factors (e.g. pharmaco-genetic variation in CYP3A4) as well as differences in clinical trials as discussed above for hypertension.

Uncontrolled high-grade hypertension can lead to serious consequences, including myocardial infarction, stroke, renal damage, and arteriosclerosis, and therefore anti-hypertensive therapy is required for managing this adverse effect in TKI patients. As TKI-induced hypertension is often associated with proteinuria, cotreatment with angiotensin-converting enzyme inhibitors (ACEI) appears a logical 
choice because ACEI are also known to improve proteinuria and prevent end-organ damage [40]. Though, angiotensin II receptor type 1 blockers (ARBs), diuretics, and $\beta$-blockers could also represent useful antihypertensive agents in treating TKIinduced hypertension, the nondihydropyridine-based calcium channel antagonists such as verapamil and diltiazem that inhibit cytochrome P450 (CYP)3A4 should be used cautiously in conjunction with anti-VEGFR TKIs that are metabolized by the same enzyme pathway [28]. Preclinical studies also suggest caution when using ARBs as they are known to inhibit receptor tyrosine kinases such as the epidermal growth factor receptor (EGFR) especially in models of diabetes with elevated angiotensin II signaling [41-43] and as such can be considered as indirect-acting TKIs in their own right. Since EGFR TKIs are known to act synergistically with VEGFR TKIs in several cancers [44,45], this might lead to a greater likelihood of onand off-target adverse effects especially if ARBs were to be used prophylactically for treating VEGFR-TKI-induced hypertension -though this clearly needs further study. In addition, the fact that VEGF-VEGFR inhibition is also associated with a paradoxical increase in the bleeding risk for some VEGF TKIs, this poses a challenging dilemma when considering anti-platelet therapy to reduce risk of myocardial ischemic in patients treated with these drugs. Thus new approaches are needed in the effective management of adverse effects with these important and effective class of anti-angiogenesis agents in cancer patients.

\section{Conclusion}

Our re-analysis of the data suggested that previous studies analyzing the risks of developing cardiovascular and hematological adverse events with VEGFR TKIs have overestimated the actual risk by using the outcome with the lower baseline risk. Our re-analysis of the adverse effects of VEGFR TKIs did, however, reveal an increase (of about $7 \%$ ) in the risk of developing hypertension which needs to be managed in these patients. In addition, there was evidence of an increased risk of bleeding with Sunitinib that warrants further investigation.

\section{Acknowledgments}

L Furuya-Kanamori was supported by an Australian National Health and Medical Research Council Fellowship (APP1158469). The research in the laboratory of S Akhtar was funded by Qatar University grant QUCG-CMED-19/20-3. 


\section{Author contributions}

Conception and design of the study: L Furuya-Kanamori and S Akhtar. Collection and assembly of the data: L Furuya-Kanamori, S Doi and S Akhtar. Analysis of the data: L Furuya-Kanamori and S Doi. Interpretation of the results: L Furuya-Kanamori, S Doi, A Onitilo and S Akhtar. Manuscript writing: L Furuya-Kanamori, S Doi, A Onitilo and S Akhtar. Final approval of manuscript: L Furuya-Kanamori, S Doi, A Onitilo and S Akhtar.

\section{Funding}

This paper was not funded.

\section{Declaration of interests}

The authors have no relevant affiliations or financial involvement with any organization or entity with a financial interest in or financial conflict with the subject matter or materials discussed in the manuscript. This includes employment, consultancies, honoraria, stock ownership or options, expert testimony, grants or patents received or pending, or royalties.

\section{Reviewer disclosures}

Peer reviewers on this manuscript have no relevant financial or other relationships to disclose. 


\section{References}

Papers of special note have been highlighted as:

* of interest

** of considerable interest

1. Viallard C, Larrivee B. Tumor angiogenesis and vascular normalization: alternative therapeutic targets. Angiogenesis. 2017;20(4):409-426.

2. Zhao Y, Adjei AA. Targeting Angiogenesis in Cancer Therapy: Moving Beyond Vascular Endothelial Growth Factor. Oncologist. 2015;20(6):660-73.

3. Touyz RM, Herrmann SMS, Herrmann J. Vascular toxicities with VEGF inhibitor therapies-focus on hypertension and arterial thrombotic events. J Am Soc Hypertens. 2018;12(6):409-425.

4. Lai $Y$, Zhao Z, Zeng $T$, et al. Crosstalk between VEGFR and other receptor tyrosine kinases for TKI therapy of metastatic renal cell carcinoma. Cancer Cell Int. 2018;18:31.

5. Abdel-Qadir H, Ethier JL, Lee DS, et al. Cardiovascular toxicity of angiogenesis inhibitors in treatment of malignancy: A systematic review and meta-analysis. Cancer Treat Rev. 2017;53:120-127.

6. Chen HX, Cleck JN. Adverse effects of anticancer agents that target the VEGF pathway. Nat Rev Clin Oncol. 2009;6(8):465-77.

7. Choueiri TK, Schutz FA, Je $Y$, et al. Risk of arterial thromboembolic events with sunitinib and sorafenib: a systematic review and meta-analysis of clinical trials. J Clin Oncol. 2010;28(13):2280-5.

*First meta-analysis on adverse events associated with VEGFR TKIs, it showed an increased risk of arterial thromobembolitic events.

8. Schutz FA, Je Y, Richards CJ, et al. Meta-analysis of randomized controlled trials for the incidence and risk of treatment-related mortality in patients with cancer treated with vascular endothelial growth factor tyrosine kinase inhibitors. J Clin Oncol. 2012;30(8):871-7.

*One of the first meta-analyses that confirmed thromboembolic events and fatal adverse events associated with VEGFR TKIs.

9. Totzeck M, Mincu RI, Mrotzek S, et al. Cardiovascular diseases in patients receiving small molecules with anti-vascular endothelial growth factor activity: A meta-analysis of approximately 29,000 cancer patients. Eur J Prev Cardiol. 2018;25(5):482-494. 
** Large meta-analysis on adverse events associated with VEGFR TKIs, the re-analysis was based on the data from this publication.

10. Furuya-Kanamori L, Doi SA. The outcome with higher baseline risk should be selected for relative risk in clinical studies: a proposal for change to practice. $J$ Clin Epidemiol. 2014;67(4):364-7.

${ }^{* *}$ Methodological paper that explains the problem of selecting the outcome with the lower baseline risk and provides a simple solution.

11. Lane PW. Meta-analysis of incidence of rare events. Stat Methods Med Res. 2013;22(2):117-32.

12. Doi SA, Barendregt JJ, Khan S, et al. Advances in the meta-analysis of heterogeneous clinical trials I: The inverse variance heterogeneity model. Contemp Clin Trials. 2015;45(Pt A):130-8.

13. Furuya-Kanamori L, Barendregt JJ, Doi SAR. A new improved graphical and quantitative method for detecting bias in meta-analysis. Int $\mathrm{J}$ Evid Based Healthc. 2018;16(4):195-203.

14. Sternberg CN, Davis ID, Mardiak J, et al. Pazopanib in locally advanced or metastatic renal cell carcinoma: results of a randomized phase III trial. J Clin Oncol. 2010;28(6):1061-8.

15. Bruix J, Qin S, Merle P, et al. Regorafenib for patients with hepatocellular carcinoma who progressed on sorafenib treatment (RESORCE): a randomised, double-blind, placebo-controlled, phase 3 trial. Lancet. 2017;389(10064):56-66.

16. Grothey A, Van Cutsem E, Sobrero A, et al. Regorafenib monotherapy for previously treated metastatic colorectal cancer (CORRECT): an international, multicentre, randomised, placebo-controlled, phase 3 trial. Lancet. 2013;381(9863):303-12.

17. Li J, Qin S, Xu R, et al. Regorafenib plus best supportive care versus placebo plus best supportive care in Asian patients with previously treated metastatic colorectal cancer (CONCUR): a randomised, double-blind, placebo-controlled, phase 3 trial. Lancet Oncol. 2015;16(6):619-29.

18. Mir O, Brodowicz T, Italiano A, et al. Safety and efficacy of regorafenib in patients with advanced soft tissue sarcoma (REGOSARC): a randomised, double-blind, placebo-controlled, phase 2 trial. Lancet Oncol. 2016;17(12):1732-1742. 
19. du Bois A, Kristensen G, Ray-Coquard I, et al. Standard first-line chemotherapy with or without nintedanib for advanced ovarian cancer (AGOOVAR 12): a randomised, double-blind, placebo-controlled phase 3 trial. Lancet Oncol. 2016;17(1):78-89.

20. Reck M, Kaiser R, Mellemgaard A, et al. Docetaxel plus nintedanib versus docetaxel plus placebo in patients with previously treated non-small-cell lung cancer (LUME-Lung 1): a phase 3, double-blind, randomised controlled trial. Lancet Oncol. 2014;15(2):143-55.

21. Cameron AC, Touyz RM, Lang NN. Vascular Complications of Cancer Chemotherapy. Canadian J Cardiol. 2016;32(7):852-62.

22. Touyz RM, Lang NN, Herrmann J, et al. Recent Advances in Hypertension and Cardiovascular Toxicities With Vascular Endothelial Growth Factor Inhibition. Hypertension. 2017;70(2):220-226.

23. Hamnvik OP, Choueiri TK, Turchin A, et al. Clinical risk factors for the development of hypertension in patients treated with inhibitors of the VEGF signaling pathway. Cancer. 2015;121(2):311-9.

24. Nazer B, Humphreys BD, Moslehi J. Effects of novel angiogenesis inhibitors for the treatment of cancer on the cardiovascular system: focus on hypertension. Circulation. 2011;124(15):1687-91.

25. Mir O, Ropert S, Alexandre J, et al. Hypertension as a surrogate marker for the activity of anti-VEGF agents. Ann Oncol. 2009;20(5):967-70.

26. Small HY, Montezano AC, Rios FJ, et al. Hypertension due to antiangiogenic cancer therapy with vascular endothelial growth factor inhibitors: understanding and managing a new syndrome. Canadian $\mathrm{J}$ Cardiol. 2014;30(5):534-43.

27. Keefe D, Bowen J, Gibson R, et al. Noncardiac vascular toxicities of vascular endothelial growth factor inhibitors in advanced cancer: a review. Oncologist. 2011;16(4):432-444.

28. Teo YL, Ho HK, Chan A. Metabolism-related pharmacokinetic drug-drug interactions with tyrosine kinase inhibitors: current understanding, challenges and recommendations. Br J Clin Pharmacol. 2015;79(2):241-53.

29. Dalbeni A, Ciccarese C, Bevilacqua M, et al. Effects of Antiangiogenetic Drugs on Microcirculation and Macrocirculation in Patients with AdvancedStage Renal Cancer. Cancers. 2019;11(1):30. 
30. van der Veldt AA, de Boer MP, Boven E, et al. Reduction in skin microvascular density and changes in vessel morphology in patients treated with sunitinib. Anticancer Drugs. 2010;21(4):439-46.

31. Eechoute $K$, van der Veldt AA, Oosting $S$, et al. Polymorphisms in endothelial nitric oxide synthase (eNOS) and vascular endothelial growth factor (VEGF) predict sunitinib-induced hypertension. Clin Pharmacol Ther. 2012;92(4):50310.

32. Safar ME, Levy BI, Struijker-Boudier H. Current Perspectives on Arterial Stiffness and Pulse Pressure in Hypertension and Cardiovascular Diseases. Circulation. 2003;107(22):2864-2869.

33. Kilickap S, Abali H, Celik I. Bevacizumab, Bleeding, Thrombosis, and Warfarin. J Clin Oncol. 2003;21(18):3542-3542.

34. Roodhart JM, Langenberg MH, Witteveen E, et al. The molecular basis of class side effects due to treatment with inhibitors of the VEGF/VEGFR pathway. Curr Clin Pharmacol. 2008;3(2):132-43.

35. Verheul HM, Pinedo HM. Possible molecular mechanisms involved in the toxicity of angiogenesis inhibition. Nat Rev Cancer. 2007;7(6):475-85.

36. Kappers $\mathrm{MH}$, van Esch JH, Sleijfer $\mathrm{S}$, et al. Cardiovascular and renal toxicity during angiogenesis inhibition: clinical and mechanistic aspects. J Hypertens. 2009;27(12):2297-309.

37. Schraermeyer $\mathrm{U}$, Julien $\mathrm{S}$. Formation of immune complexes and thrombotic microangiopathy after intravitreal injection of bevacizumab in the primate eye. Graefes Arch Clin Exp Ophthalmol. 2012;250(9):1303-13.

38. Yang $R$, Thomas GR, Bunting $S$, et al. Effects of vascular endothelial growth factor on hemodynamics and cardiac performance. J Cardiovasc Pharmacol. 1996;27(6):838-44.

39. Mourad JJ, Levy BI. Mechanisms of antiangiogenic-induced arterial hypertension. Curr Hypertens Rep. 2011;13(4):289-93.

40. Izzedine H, Ederhy S, Goldwasser F, et al. Management of hypertension in angiogenesis inhibitor-treated patients. Ann Oncol. 2009;20(5):807-15.

41. Akhtar S, El-Hashim AZ, Chandrasekhar B, et al. Naked Polyamidoamine Polymers Intrinsically Inhibit Angiotensin II-Mediated EGFR and ErbB2 Transactivation in a Dendrimer Generation- and Surface ChemistryDependent Manner. Mol Pharm. 2016;13(5):1575-86. 
42. Akhtar S, Yousif MH, Chandrasekhar B, et al. Activation of EGFR/ERBB2 via pathways involving ERK1/2, P38 MAPK, AKT and FOXO enhances recovery of diabetic hearts from ischemia-reperfusion injury. PloS One. 2012;7(6):e39066.

43. Forrester SJ, Kawai T, O'Brien S, et al. Epidermal Growth Factor Receptor Transactivation: Mechanisms, Pathophysiology, and Potential Therapies in the Cardiovascular System. Annu Rev Pharmacol Toxicol. 2016;56:627-53.

44. Dienstmann R, Brana I, Rodon J, et al. Toxicity as a biomarker of efficacy of molecular targeted therapies: focus on EGFR and VEGF inhibiting anticancer drugs. Oncologist. 2011;16(12):1729-40.

45. Tabernero J. The role of VEGF and EGFR inhibition: implications for combining anti-VEGF and anti-EGFR agents. Mol Cancer Res. 2007;5(3):20320. 
Table 1. Updated risk (relative risks and its $95 \%$ confidence intervals) profile for VEGFR TKIs using the complementary outcome for 11 adverse events

\begin{tabular}{|c|c|c|c|c|c|c|c|c|c|}
\hline & Overall & Axitinib & Levantinib & Nintedanib & Pazopanib & Regorafenib & Sorafenib & Sunitinib & Vandetanib \\
\hline Thrombotic & $1.00(0.99-1.00)$ & - & - & $0.99(0.97-1.01)$ & $0.99(0.98-1.01)$ & 1.0 & $1.00(0.54-1.83)$ & $1.00(0.99-1.01)$ & $1.01(0.96-1.06)$ \\
\hline Arterial thrombotic & $1.00(0.98-1.01)$ & $1.01(0.98-1.04)$ & - & $1.00(0.99-1.01)$ & $0.96(0.93-0.99)$ & & - & - & - \\
\hline $\begin{array}{l}\text { Myocardial } \\
\text { infarction }\end{array}$ & $1.00(0.99-1.00)$ & - & $1.00(0.99-1.02)$ & $1.00(0.99-1.00)$ & $0.98(0.96-1.00)$ & & $1.00(0.99-1.01)$ & $1.00(1.00-1.01)$ & $1.03(0.95-1.12)$ \\
\hline Stroke & $1.00(1.00-1.00)$ & $1.00(0.99-1.01)$ & $0.99(0.98-1.01)$ & $1.00(1.00-1.00)$ & $0.99(0.98-1.01)$ & & $1.00(1.00-1.01)$ & $1.00(0.99-1.01)$ & $0.97(0.89-1.06)$ \\
\hline Venous thrombotic & $1.00(0.99-1.01)$ & $1.00(0.98-1.02)$ & $0.99(0.96-1.02)$ & $0.99(0.97-1.02)$ & $0.97(0.93-1.01)$ & - & $0.99(0.98-1.01)$ & $0.99(0.97-1.00)$ & $1.01(0.99-1.02)$ \\
\hline $\begin{array}{l}\text { Pulmonary } \\
\text { embolism }\end{array}$ & $1.00(1.00-1.01)$ & $1.00(0.99-1.02)$ & $0.99(0.96-1.02)$ & $1.00(1.00-1.01)$ & $0.94(0.82-1.09)$ & $1.01(0.98-1.04)$ & $1.04(0.92-1.18)$ & $0.99(0.99-1.00)$ & $1.00(0.99-1.01)$ \\
\hline Bleeding & $0.99(0.96-1.06)$ & $0.98(0.86-1.11)$ & - & $0.96(0.93-0.99)$ & & $0.94(0.85-1.04)$ & $1.00(0.92-1.08)$ & $0.49(0.34-0.69)$ & $0.99(0.95-1.04)$ \\
\hline Thrombocytopenia & $0.98(0.90-1.08)$ & $1.00(0.97-1.02)$ & $1.00(0.98-1.01)$ & $0.90(0.70-1.15)$ & $1.08(0.66-1.74)$ & $0.91(0.89-0.93)$ & $0.99(0.88-1.12)$ & $0.92(0.78-1.07)$ & $0.94(0.86-1.02)$ \\
\hline $\begin{array}{l}\text { Left ventricular } \\
\text { dysfunction }\end{array}$ & $1.00(0.99-1.00)$ & $1.00(0.99-1.02)$ & - & & $1.00(0.95-1.04)$ & $0.99(0.95-1.03)$ & $1.00(0.99-1.00)$ & $1.00(0.98-1.01)$ & $1.00(0.98-1.01)$ \\
\hline $\begin{array}{l}\text { QTc interval } \\
\text { prolongation }\end{array}$ & $0.99(0.98-1.00)$ & $1.00(0.99-1.01)$ & - & & $1.00(0.99-1.01)$ & - & - & $0.99(0.98-1.00)$ & $0.98(0.95-1.01)$ \\
\hline Hypertension & $0.93(0.88-0.97)$ & $0.86(0.66-1.11)$ & $0.35(0.29-0.43)$ & $0.97(0.92-1.02)$ & $0.64(0.48-0.86)$ & $0.79(0.72-0.87)$ & $0.92(0.85-0.99)$ & $0.95(0.90-1.00)$ & $0.90(0.78-1.05)$ \\
\hline
\end{tabular}

Green: No increase in risk

Yellow: $<10 \%$ increase in risk

Red: $>10 \%$ increase in risk 


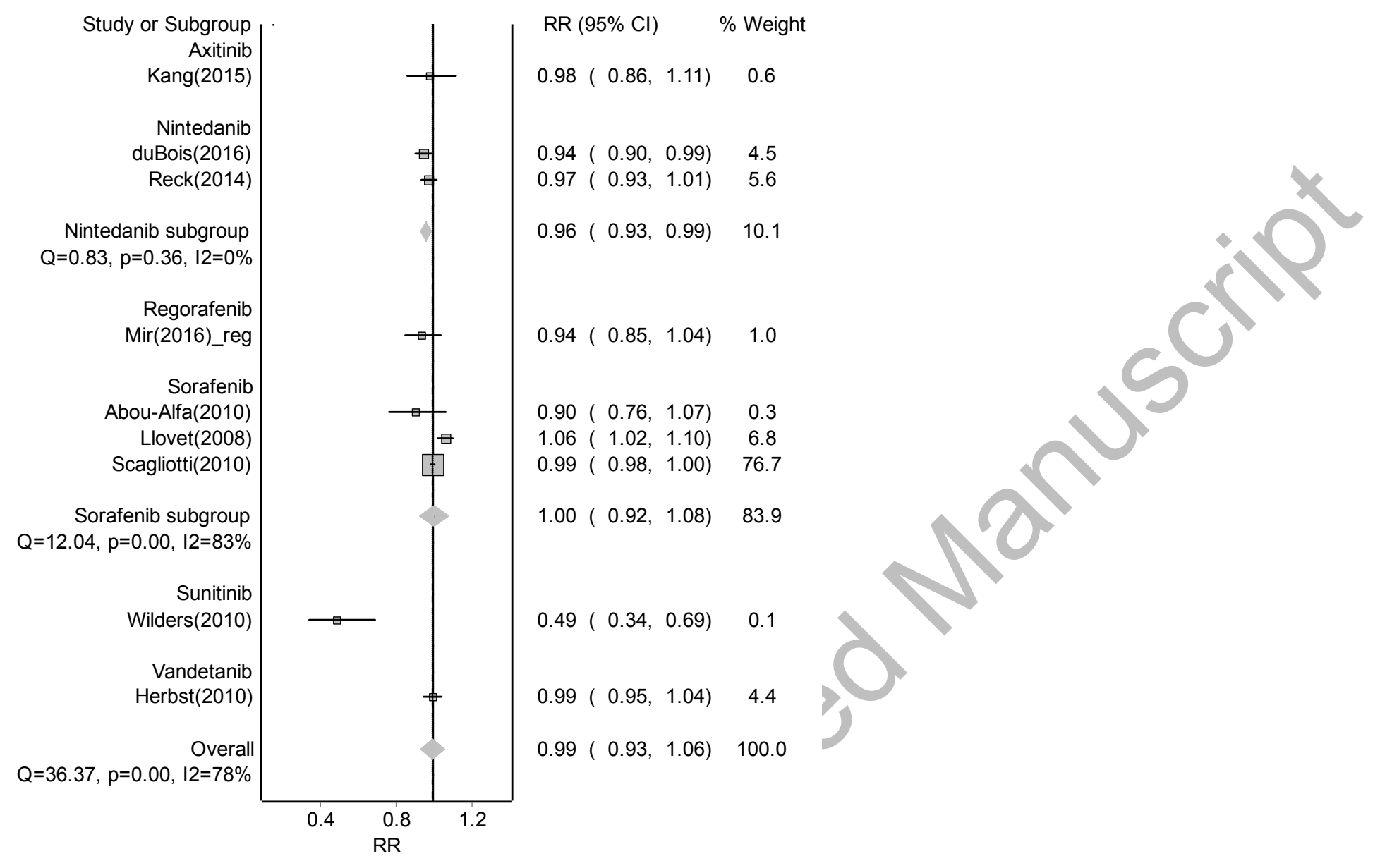

Figure 1. Forest plot for the risk of bleeding by the type of VEGFR TKIs using the complementary outcome 


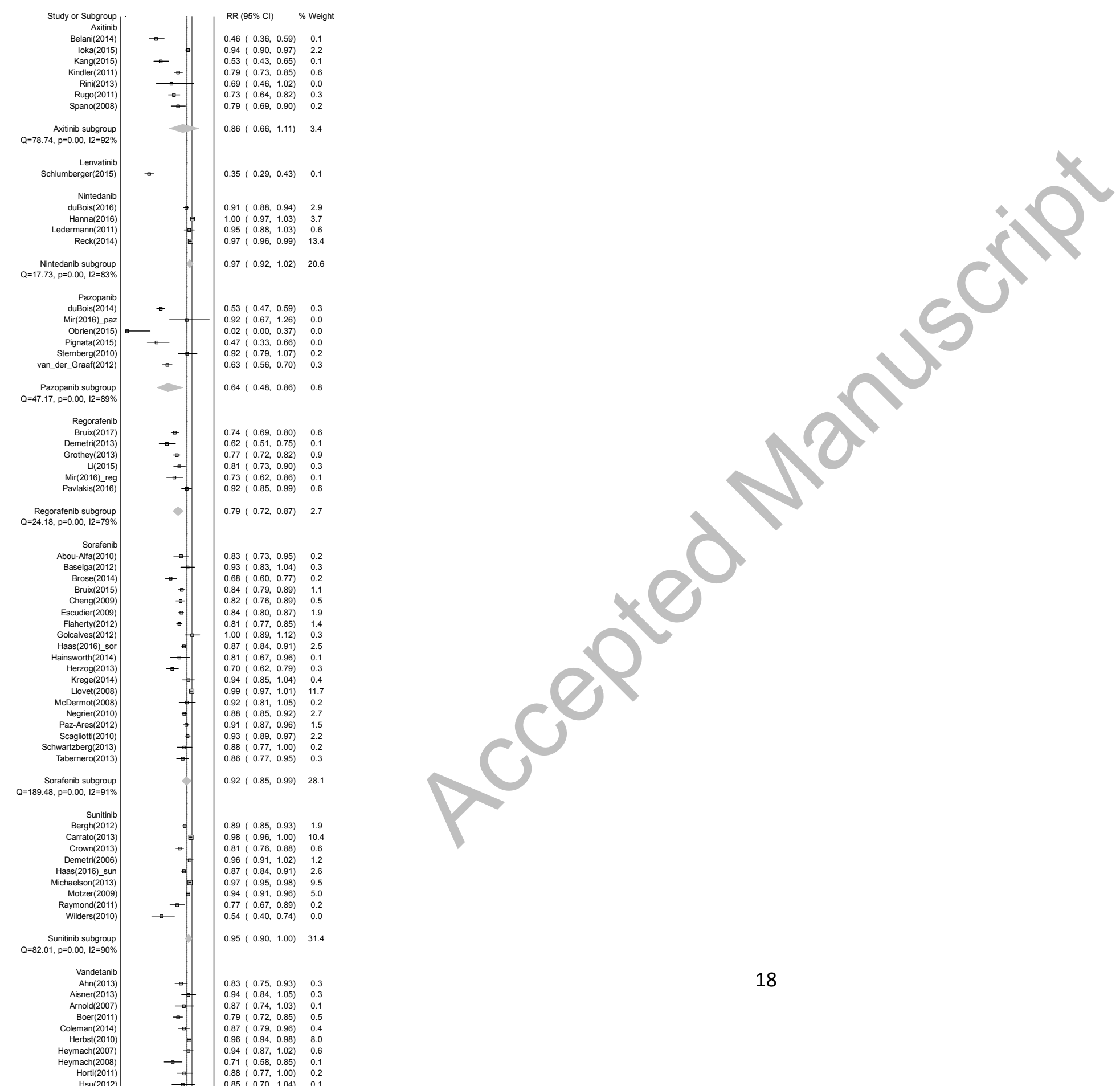


Figure 2. Forest plot for the risk of hypertension by the type of VEGFR TKIs using the complementary outcome

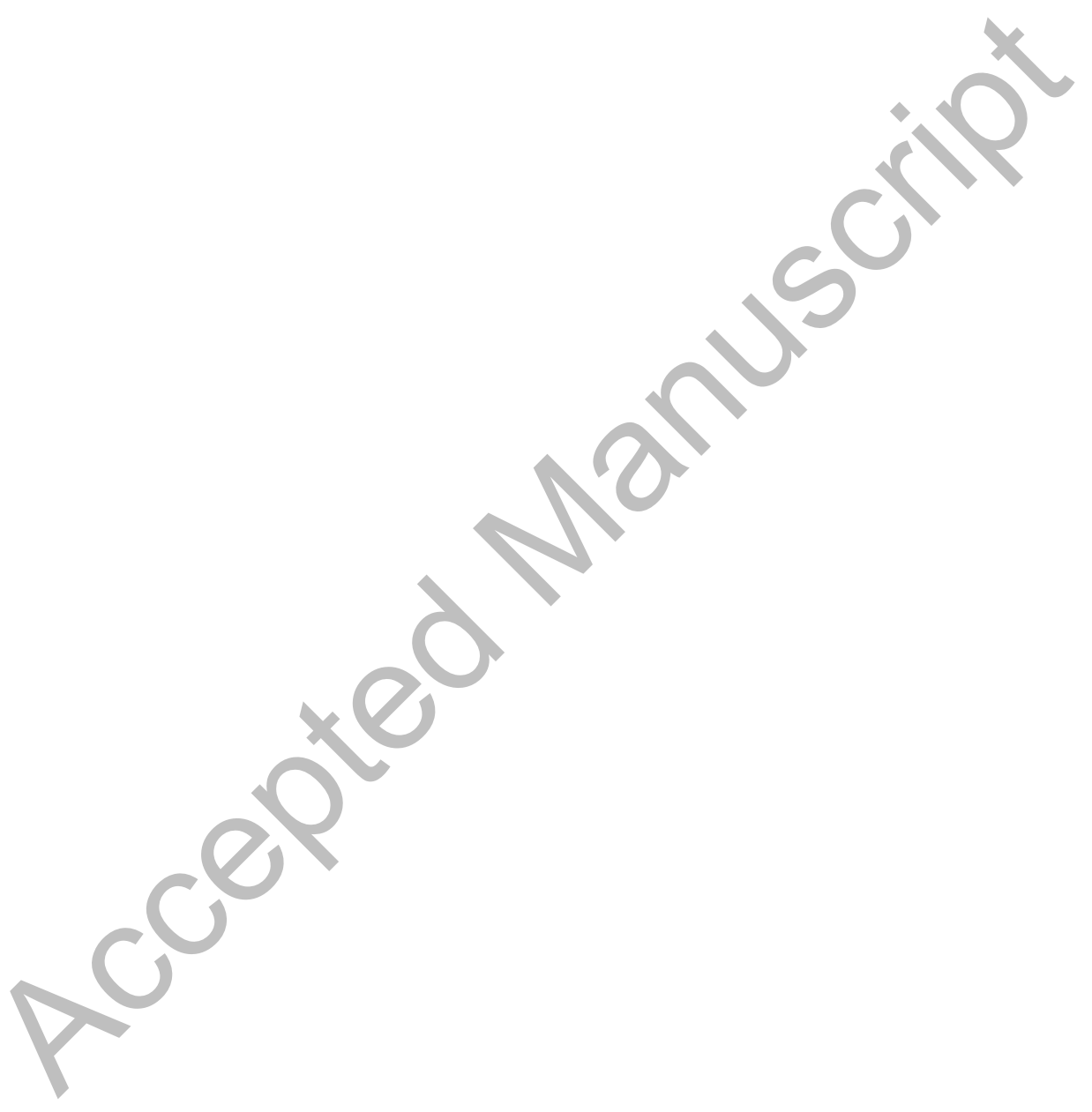




\section{Supplementary material}

S1. The number needed to harm (and its 95\% confidence intervals) for VEGFR TKIs using the complementary outcome for 11 adverse events

\begin{tabular}{|c|c|c|c|c|c|c|c|c|c|}
\hline & Overall & Axitinib & Levantinib & Nintedanib & Pazopanib & Regorafenib & Sorafenib & Sunitinib & Vandetanib \\
\hline Thrombotic & $\mathrm{n} / \mathrm{a}$ & - & - & $\mathrm{n} / \mathrm{a}$ & $\mathrm{n} / \mathrm{a}$ & $\mathrm{n} / \mathrm{a}$ & $\mathrm{n} / \mathrm{a}$ & $\mathrm{n} / \mathrm{a}$ & $\mathrm{n} / \mathrm{a}$ \\
\hline Arterial thrombotic & $\mathrm{n} / \mathrm{a}$ & $\mathrm{n} / \mathrm{a}$ & - & $\mathrm{n} / \mathrm{a}$ & $26(15-132)$ & - & - & - & - \\
\hline $\begin{array}{l}\text { Myocardial } \\
\text { infarction }\end{array}$ & $\mathrm{n} / \mathrm{a}$ & - & $\mathrm{n} / \mathrm{a}$ & $\mathrm{n} / \mathrm{a}$ & $\mathrm{n} / \mathrm{a}$ & & $\mathrm{n} / \mathrm{a}$ & $\mathrm{n} / \mathrm{a}$ & $\mathrm{n} / \mathrm{a}$ \\
\hline Stroke & $\mathrm{n} / \mathrm{a}$ & $\mathrm{n} / \mathrm{a}$ & $\mathrm{n} / \mathrm{a}$ & $\mathrm{n} / \mathrm{a}$ & $\mathrm{n} / \mathrm{a}$ & & $\mathrm{n} / \mathrm{a}$ & $\mathrm{n} / \mathrm{a}$ & $\mathrm{n} / \mathrm{a}$ \\
\hline Venous thrombotic & $\mathrm{n} / \mathrm{a}$ & $\mathrm{n} / \mathrm{a}$ & $\mathrm{n} / \mathrm{a}$ & $\mathrm{n} / \mathrm{a}$ & $\mathrm{n} / \mathrm{a}$ & - & $\mathrm{n} / \mathrm{a}$ & $\mathrm{n} / \mathrm{a}$ & $\mathrm{n} / \mathrm{a}$ \\
\hline $\begin{array}{l}\text { Pulmonary } \\
\text { embolism }\end{array}$ & $\mathrm{n} / \mathrm{a}$ & $\mathrm{n} / \mathrm{a}$ & $\mathrm{n} / \mathrm{a}$ & $\mathrm{n} / \mathrm{a}$ & & $\mathrm{n} / \mathrm{a}$ & $\mathrm{n} / \mathrm{a}$ & $\mathrm{n} / \mathrm{a}$ & $\mathrm{n} / \mathrm{a}$ \\
\hline Bleeding & $\mathrm{n} / \mathrm{a}$ & $\mathrm{n} / \mathrm{a}$ & - & $28(17-104)$ & & $\mathrm{n} / \mathrm{a}$ & $\mathrm{n} / \mathrm{a}$ & $2(1-4)$ & $\mathrm{n} / \mathrm{a}$ \\
\hline Thrombocytopenia & $\mathrm{n} / \mathrm{a}$ & $\mathrm{n} / \mathrm{a}$ & $\mathrm{n} / \mathrm{a}$ & $\mathrm{n} / \mathrm{a}$ & $1 / \mathrm{a}$ & $12(10-15)$ & $\mathrm{n} / \mathrm{a}$ & $\mathrm{n} / \mathrm{a}$ & $\mathrm{n} / \mathrm{a}$ \\
\hline $\begin{array}{l}\text { Left ventricular } \\
\text { dysfunction }\end{array}$ & $\mathrm{n} / \mathrm{a}$ & $\mathrm{n} / \mathrm{a}$ & - & & $\mathrm{n} / \mathrm{a}$ & $\mathrm{n} / \mathrm{a}$ & $\mathrm{n} / \mathrm{a}$ & $\mathrm{n} / \mathrm{a}$ & $\mathrm{n} / \mathrm{a}$ \\
\hline $\begin{array}{l}\text { QTc interval } \\
\text { prolongation }\end{array}$ & $\mathrm{n} / \mathrm{a}$ & $\mathrm{n} / \mathrm{a}$ & - & & $\mathrm{n} / \mathrm{a}$ & - & - & $\mathrm{n} / \mathrm{a}$ & $\mathrm{n} / \mathrm{a}$ \\
\hline Hypertension & $15(10-40)$ & $\mathrm{n} / \mathrm{a}$ & $2(1-3)$ & $\mathrm{n} / \mathrm{a}$ & $4(3-10)$ & $4(4-9)$ & $12(17-117)$ & $\mathrm{n} / \mathrm{a}$ & $\mathrm{n} / \mathrm{a}$ \\
\hline
\end{tabular}

n/a not applicable, no association between the exposure (i.e. VEGFR TKIs) and the outcome (i.e. adverse events) 


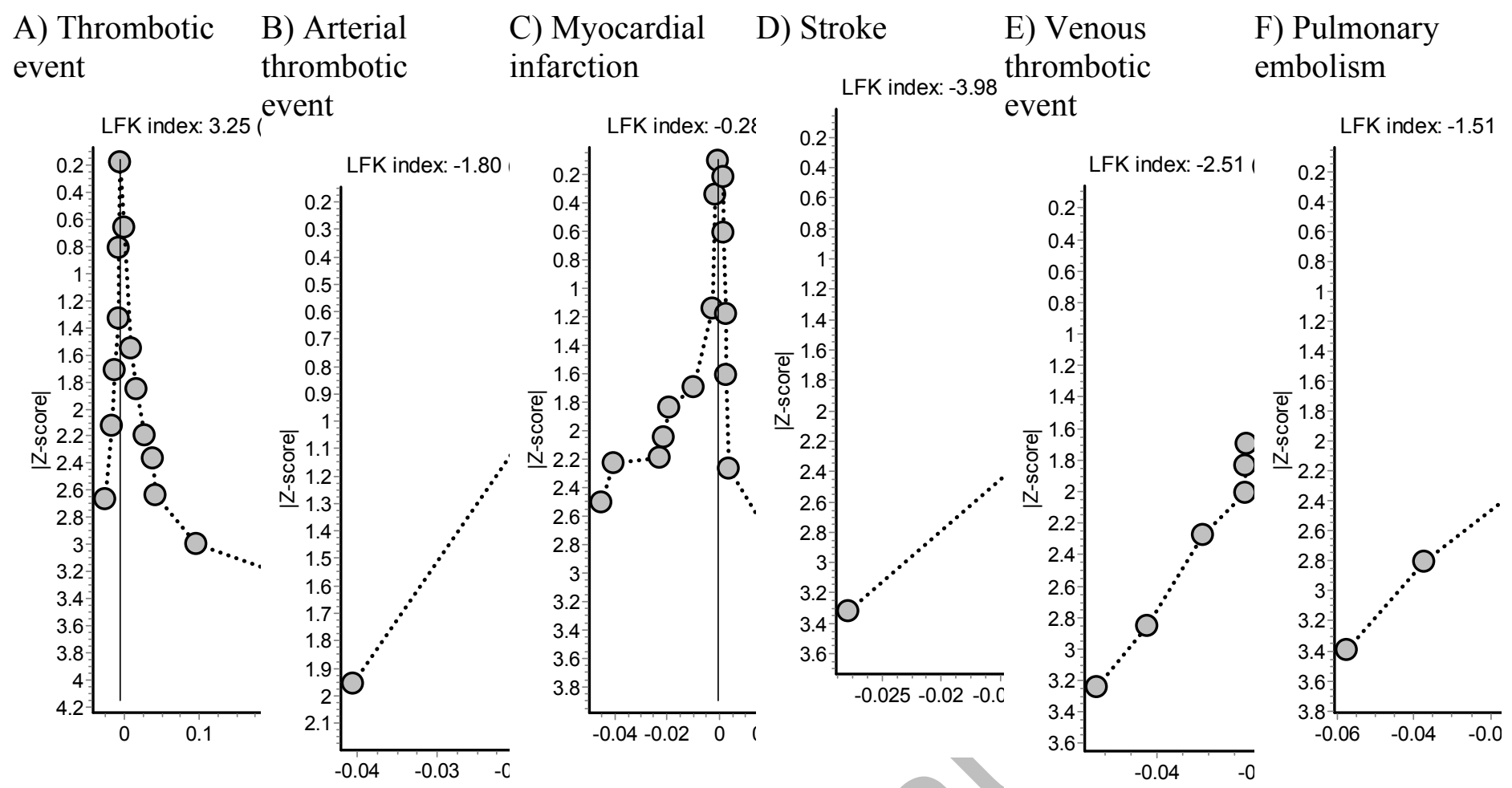

G) Bleeding

H)

I) Left

J) QTc

K)

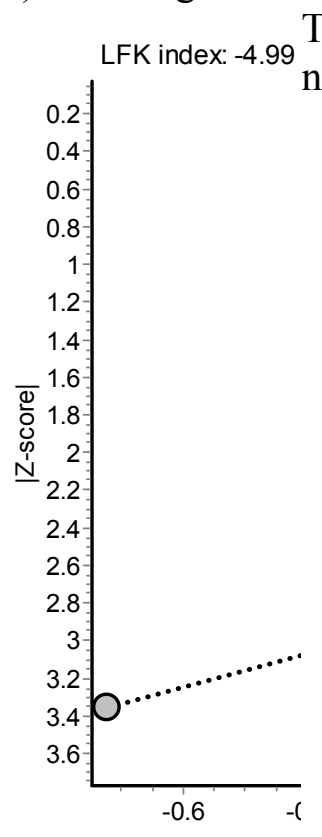

Thrombocytope

ventricular

prolongation

Hypertension

dysfunction
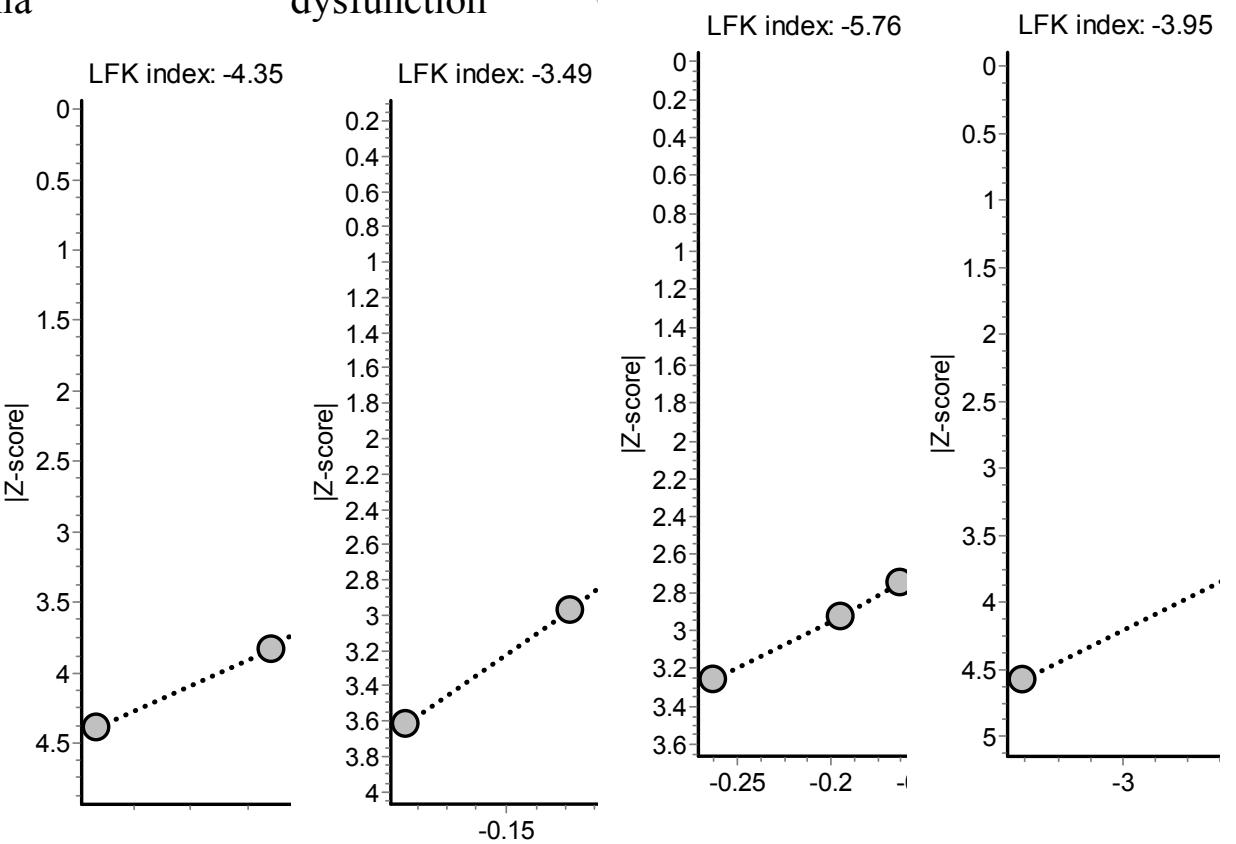

S2. Doi plot and LFK index value a) thrombotic; b) arterial thrombotic; c) myocardial infarction; d) stroke; e) venous thrombotic; f) pulmonary embolism; g) bleeding; h) thrombocytopenia; i) left ventricular dysfunction; j) QTc interval prolongation; and k) hypertension 